\title{
CURRENT INFANT FEEDING PRACTICES IN EGOR LOCAL GOVERNMENT AREA OF EDO STATE
}

\author{
M.O. Ibadin, P.O. Abiodun, J. Akpan \\ Department of Child Health, University of Benin Teaching Hospital, Benin, Nigeria
}

The provision of appropriate nutrition is of great importance during infancy and childhood in support of rapid growth and development inherent in these periods. Many initiatives have been started in the past decades and this study was carried out To assess what further progress may have been made in actualising optimal infant feeding practices in Benin City in the intervening decades, a community-based household survey was carried out .

Infant feeding practices were evaluated using pre-tested questionnaires on 1068 mothers of infants aged less than 12 months.

546 (51.1\%) infants were aged 0-5 months. The Ever Breastfed Rate of 99.5\% was indicative of a high prevalence of breastfeeding in the community. The Time Suckling Rate of $35.4 \%$ was comparable to the national average of $32 \%$. The Exclusive and Predominant Breastfeeding Rates of $40.7 \%$ and $30.4 \%$ respectively, have remained relatively stable over the past decade. The Bottle-feeding Rate was $28.9 \%$. Significant determinants of optimal breastfeeding were high maternal education $\left(X^{2}=9.718 ; p=0.045\right)$, high socio-economic status $\left(X^{2}=12.910 ; p=0.012\right)$, increasing maternal age $\left(X^{2}=14.777 ; p=0.022\right)$, higher parity $\left(X^{2}=15.212 ; \mathrm{p}=0.009\right)$, delivery in hospital $\left(\mathrm{X}^{2}=15.079 ; \mathrm{p}=0.020\right)$ and infant age $\left(\mathrm{X}^{2}=\right.$ $100.482 ; \mathrm{P}=0.0001)$.

Breastfeeding practices in Benin City have not improved much from what obtained a decade ago. Greater emphasis on female education,socio-economic empowerment and improved funding of the Baby-friendly Hospital Initiative is advocated. 